\section{RESEARCHES OF INFANT'S CRY}

N. Bolfan-Stosic, D. Blazi

Department of Speech, Language and Voice Pathology, Faculty of Special Education and Rehabilitation University of Zagreb, Zagreb,

\section{Croatia}

This paper is a review of infant's cry acoustic analysis in Croatia. The purpose of all researches is establishing acoustical characteristics of infant's cries as a help in diagnostic of voice disorders. The research from 2000. analyzed two types of seven cries: very first cry (birth stimulus) and following continues signal. Results of acoustic analysis indicate better cry characteristics in continues signal after first cry characterized by noise and strong frequency oscillations. The second research from 2001. shows differences in fundamental tone frequencies between two days old girl with intracranial bleeding and healthy girl. The fundamental frequency of the healthy girl's cry was $47.8 \mathrm{~Hz}$ lower than the fundamental frequency of the sick girl. The main purpose of the third research from 2001. was to follow acoustical voice characteristics of boy and girl to first word production. Different types of vocalizations were analyzed from 2 . to 11 . month of life (in five different time periods). The fourth research from 2006. showed results of acoustic analysis of voice of newborn babies as a function of discrimination of specific voice features in premature born babies. Premature birth represents potential risk for overall infant development. Some differences were established: premature born babies showed significantly higher fundamental frequency (over $600 \mathrm{~Hz}$ ), larger fundamental frequency range, less sound energy in the voice and more uneven sound realization of cries than controls did. The several voice analysis programs were used in all researches of this review (MDVP, Gram 2.3., EZ Voice Plus).

\section{1}

\section{THE CAREER CHOICES OF STUDENTS UNDERTAKING THE 4.5 YEAR CHILDREN'S AND GENERAL NURSING INTEGRATED PROGRAMME IN THE REPUBLIC OF IRELAND}

\section{E. Hollywood}

\section{School of Nursing \& Midwifery, Trinity College Dublin, Dublin, Ireland}

Aim: To ascertain the factors which influence where students undertaking the 4.5 year Children's and
General Nursing Integrated programme intend to practice post graduation.

Background: Children's nurse education in the Republic of Ireland has undergone radical change in the past decade. In September 2006 the first BSc in Children's and General Nursing Integrated Programme commenced nationally. The programme was introduced in an effort to increase the numbers of students studying to become children's nurses and also to provide a children's nurse education programme at undergraduate level in the Republic of Ireland. The programme is four and a half years in duration and graduates will obtain a Bachelor of Science in Children's and General Nursing. Successful graduates will therefore be eligible to register as both Registered Children's Nurses and Registered General Nurses with An Bord Altranis (the Irish Nursing Board). This means that graduates will be 'dual qualified' and subsequently can choose to work in either area.

Methodology: A quantitative approach was adopted and data were gathered by means of a 19 point specifically designed questionnaire. Purposive sampling was utilised to access all $3^{\text {rd }}$ and $4^{\text {th }}$ year nursing students of the General and Children's Nursing Integrated programme $(n=200)$. SPSS version 16 was used to analyse data.

Results: Students have clear ideas about where they intend to practice post graduation. Participants reported enjoying practicing as children's nurses more than practicing as general nurses. Participants also reported perceiving greater job satisfaction working as a children's nurse that as a general nurses.

\section{2}

\section{AN INTERPRETATION OF THE CHILDREN'S NURSING CONTENT OF UNDERGRADUATE NURSING PROGRAMMES IN THE REPUBLIC OF IRELAND}

\section{E. Hollywood, H. Nicholl, M. Murphy, T. Begley, C. King \\ School of Nursing \& Midwifery, Trinity College Dublin, Dublin, Ireland}

Caring for the hospitalised child and their family in the 21 st century is extremely challenging. This great challenge has evolved as a result in technological advances, increased emphasis on family-centered care, ambulatory care and community care. 